Frontiers: The Interdisciplinary Journal of Study Abroad

(C) 2021 Linda Dunn-Jensen, Joyce Osland, Pamela Wells

The work is licensed under the Creative Commons Attribution-NonCommercial-NoDerivatives 4.0

International License.

Volume 33, Issue 1, pp. 206-230

DOI 10.36366/frontiers.v33i1.520

FORUM

ON EDUCATION

ABROAD

\title{
To Understand You, I Need to Know Me:
} Approximating the Study Abroad Experience Utilizing Assessment as Learning in a Glocal Classroom

Linda M. Dunn-Jensen', Joyce S. Osland², Pamela M. Wells²

\begin{abstract}
Due to Covid-19 and the inaccessibility of study abroad for some students, we successfully tested an alternative for building intercultural effectiveness-a glocal classroom (GC) pedagogy highlighting assessment as learning. Over a 15-week course, the GC replicated the work context and job demands of expert global leaders and developed global skills via activities and simulations. Pre- and post-test measures of the Intercultural Effectiveness Scale (IES) found significant improvement in all dimensions. Students with prior international experience had higher pretest results in the world orientation and relationship development dimensions; however, students without study abroad experience approximated those results in their posttest assessment, apparently as a result of the GC. Quantitative findings suggest that assessment, self-awareness, self-directed PDPs, well-designed simulations, receiving and giving extensive feedback, and reflection can be effective methods for moving the needle on intercultural competencies without a physical international experience.
\end{abstract}

\section{Keywords:}

assessment, glocal classroom, pedagogy, study abroad, global leadership development, intercultural competence.

1 California State University, Stanislaus, Turlock, CA, USA

2 SAn Jose State University, SAN Jose, CA, USA

Corresponding author: Linda Dunn-Jensen, Idunnjensen@csustan.edu 


\section{The Need for An Alternative to Study Abroad}

Study abroad is a well-accepted method for developing intercultural competencies and global skills. Indeed, over the past $30+$ years, colleges and universities have seen a steady increase of students studying abroad, both inbound and outbound (IIE, 2019). This paper researches an alternative method that addresses two longstanding criticisms of study abroad programs, while also acknowledging the impact of COVID-19. The global pandemic added a new impediment to study abroad by abruptly halting international programs, returning students to their home countries, and injecting enormous uncertainty concerning when programs can safely reopen. International educators are left searching for reasonable alternatives that serve the same function as study abroad and also avoid the following perceived drawbacks.

First, despite study abroad's growing global popularity, particularly in the U.S. context where this study took place, barriers to participation prevent some students from taking advantage of study abroad opportunities. Perceived cost is a key prohibiting factor (West, 2019). Since most study abroad students rely on funding from either family or personal funds (IIE, 2019), a participation gap in the United States between underrepresented, lower-income minorities and their White counterparts is not surprising. According to the IIE report (2019), African-Americans made up only $6.1 \%$ and Latinx students made up $10.6 \%$ of all U.S. students who studied abroad, while White students comprised $70 \%$. Even after taking into consideration the lower percentage of minorities in higher education, these percentages are low (West, 2019).

Second, critics warn that study abroad does not automatically result in guaranteed increases in intercultural competence and global skills (Vande Berg, et al., 2012; Lokkesmoe, et al., 2016). Program designs vary in their focus and impact, not all students are equally prepared and motivated to take advantage of self-development opportunities, and unpredictable personal experiences abroad do not always lead to positive learning.

Admittedly, some of the same criticism can be leveled at classroom attempts to develop global and intercultural skills. However, with the use of assessment, carefully designed highimpact pedagogy, and in-depth instructor training, it is plausible that students will report progress in a glocal classroom designed to replicate global challenges. Thus, as an alternative to study abroad, we propose an accessible glocal classroom pedagogy that utilizes assessment as a method of learning (Acheson et al., 2020, Rowe, 2012), a personal development process based on cognitive behavior therapy (Butler, et al., 2006), transformative education (Mezirow et al., 1990), carefully designed experiential activities (Kolb, 1984), and formative assessment (Yorke, 2003). To demonstrate its effectiveness, we report findings of a pre and post measure of intercultural effectiveness that yielded results similar to those that can be attained in highimpact study abroad experiences.

\section{Conceptual Foundations}

The Glocal Classroom (GC) pedagogy used in the course design was developed in a Global Leadership Laboratory at a large, diverse state university on the West Coast. The GC pedagogy and learning activities are rooted in research and best practices from multiple 
disciplines (e.g., global leadership development, intercultural competence, international education, experiential learning). The GC functions as an assessment center (Deters, 2017; Osland, et al., 2017; Herd, et al., 2018), which means that students take a battery of personal assessment instruments and receive feedback from various sources on their behavior in simulations and an extensive multicultural team project. Based on these data, students create a Personal Development Plan that is predicated on cognitive behavior therapy (CBT) and formative assessment. (For a more comprehensive description of the GC and how it functions, see Osland et al., 2017.) The GC's conceptual and theoretical underpinnings are briefly described in the following paragraphs.

\section{Intercultural Competence and its Development}

There is a lack of consensus among scholars on the definition of competency, intercultural or otherwise (Acheson \& Schneider-Bean, 2019; Shipmann, et al., 2000). Building on Mendenhall, et al.'s (2017) review of this construct and Bennett's (2008) definition of intercultural competence, we define intercultural competence as the knowledge, skills, abilities or other characteristics (which includes attitudes and behaviors) required for effective and appropriate intercultural interactions in a variety of cultural contexts. For example, intergroup appropriateness concerns the extent to which communicative behavior "matches the social group expectations of the message's recipients" (Ting-Toomey\& Dorjee, 2019, p. 141). Deardorff (2011) acknowledges the inherent complexity of intercultural competence since effective intercultural interactions are both subjective and context specific. Appropriate behavior in one intercultural context may be inappropriate in a different setting or with diverse people (Osland \& Bird, 2000). Competency lies in recognizing and understanding these nuanced differences, accepting them, and behaving appropriately.

Because total immersion in another culture is the foundation of study abroad programs, its effectiveness in teaching intercultural skills and preparing students for global work is often assumed, unless a pre and post assessment is done. The research on study abroad outcomes at the student level, however, shows mixed results, ranging from reports of being "transformed" by the experience to having a great opportunity to party in a foreign venue (Vande Berg et al., 2012). Furthermore, at the program level, typical findings include program designs that do not encourage contact with the local culture and only moderate gains in cultural learning (e.g., Vande Berg, 2007; 2009).

According to Deardorff (2011), developing intercultural competence is not an event (or a trip), but instead an ongoing focused process; simply interacting with diverse others and studying and reading about other cultures does not guarantee the development of intercultural competence. Indeed, learning how to think about culture is more important than simply learning about culture (Bok, 2006; Deardorff, 2011). In addition, understanding how to monitor one's thinking and recognize one's assumptions about culture increases intercultural learning (Morris et al., 2019), and being mindful (i.e. awareness of one's own assumptions and mental models, open-mindedness, ability to create new mental models when necessary, awareness of context, and empathy), is a key component for cultural intelligence (Thomas, 2006). Hence, an effective approach to developing intercultural competencies should include a method that encourages and allows students an opportunity to become aware of their schemas about culture, question cultural assumptions, adapt their thinking and behaviors appropriately, and 
assess both developmental growth and impact as well as content knowledge. The GC utilizes three different types of assessment that are described below, and accompanied by a brief example of the GC application.

\section{Assessment of Learning vs. Assessment as Learning}

In both domestic and international education, assessment is commonly used to measure program learning goals and outcomes, as well as learners' mastery of the subject matter (Acheson, et al., 2020). This common approach to assessment can be described as assessment of learning (Acheson, et al., 2020; Rowe, 2012). In the GC, content knowledge is assessed with frequent quizzes and a mid-term exam; the skill-based course learning objectives are assessed by a behavioral exam at the end.

Assessment is less commonly employed to measure students' self-awareness of what they know (or think they know), in addition to, or in relationship to, the subject matter and student directed learning goals (setting and attaining) based on new self-insights. Termed assessment as learning (Acheson, et al., 2020; Rowe, 2012), this use of assessment provides an opportunity to create learning in its own right by acting as a building block for metacognitive development. According to Schraw (1998), metacognition can be defined as the awareness of what and how one thinks, and the ability to regulate one's thinking. People think, act, and respond in ways that are familiar to them but frequently have no real understanding of their underlying cognitive processes and motivations. A great deal of learning is implicit, which leads to shortcuts in cognitive processing, resulting in heuristic judgments, automatic behaviors and mindless thinking (Langer \& Moldoveanu, 2000; Morris, et al., 2019). Because mindfulness is so crucial in intercultural relations (e.g., Thomas, 2006), GC reflections and simulation debriefs provide an assessment as learning mode for self-insight and studentdirected learning that involves several action steps for both individuals and teams. For example, GC simulations (The Owl and Alpha Beta simulations - see Table 1) and an intercultural video test (Star Trek - see Table 1) are designed specifically to help students make their thinking explicit with respect to overarching course learning objectives, such as decoding cultural differences, code-switching behaviors to adapt to other cultures, and identifying effective and ineffective cross-cultural behaviors.

\section{Formative Assessment}

Research indicates a need for formative assessment in education (OECD, 2005; Weurlander, et al., 2012; Yorke, 2003). Formative assessment is a process of personal feedback used in conjunction with other types of assessment to help students engage with and better understand the subject matter and subsequently personalize it for their own understanding (Weurlander, et al., 2012). Yorke (2003) categorized formative feedback as formal or informal; formal feedback relates to feedback on students' work with respect to assignment criteria and is typically asynchronous, while informal feedback is real-time feedback about performance in, for example, a group activity or experiential exercise. Both types of feedback can have a single rater or multiple-rater sources (i.e., instructor, peers, self, observers) and support the idea of assessment as learning. Thus, formative assessment can be thought of as an active form of assessment that personally engages students. For example, one GC strategy used in debriefing simulations is the encouragement of "do-overs," which allow students (and faculty) 
an opportunity to rephrase comments in a more effective manner. "What would be a more effective way of stating that?" This strategy helps students begin to internalize how others respond to comments, gain empathy and learn to be more effective, thereby increasing their intercultural competence.

In the GC, simulations were a source of extensive informal feedback in real time. Students often evaluated themselves and peers with the help of specific behavioral rubrics. However, they were also taught to give and receive verbal personal feedback in simulations. This worked best when the stage was set correctly. On the first day of class, instructors announced that prior classes demonstrated significant personal growth and progress in developing competencies, cautioning that this only happened when students were willing to work at it and were willing to receive personal feedback. Instructors then asked the students if they were open to this type of feedback and if they really wanted to take part in a nontraditional GC course that would make different demands on them. These questions, along with the reliance on a behavioral final exam, created a "promise" between the instructor and students similar to a psychological contract (Rousseau, 1995) that students were expected to improve skills and take advantage of reflection, feedback, and practice throughout the course in return for coaching and feedback that would hopefully benefit their personal and work lives. The questions also acknowledged that feedback is more effective when solicited, not imposed (Ashford \& Tsui, 1991), and helped move students from a "decision to join" a class to the “decision to participate” (March \& Simon, 1963).

The GC used an activity (the Daimler Simulation - see Table 1) toward the end of the course that tested global team leadership skills as well as the ability to give and receive feedback. A multicultural team composed of volunteers from the class evaluated their own behavior in a role play observed by the entire class and then received structured feedback from multiple sources: 1) another role play member, 2) a group of class observers focused solely on one volunteer, and 3) the instructor. Everyone learned from this real-time formative assessment how specific verbal and non-verbal behavior impacted team members and their output.

\section{Transformative Learning Theory}

Transformative learning theory (Mezirow, 1978) is triggered by a disorienting experience that makes uncertain something previously viewed as certain. Mezirow defines transformative learning as "learning that transforms problematic frames of reference to make them more inclusive, discriminating, reflective, open, and emotionally able to change” (2003, p. 58). He identified a three-stage process comprised of exposure to a trigger event (contrast), critical self-examination and reflection about beliefs and experiences and questioning underlying assumptions (confrontation), and changing one's worldviews, potentially transforming values, beliefs and identity (replacement) (Mezirow, 1978). These practices are highly relevant for developing intercultural understanding and a global mindset. The GC's assessment results and challenging activities function as trigger events while the reflection and sense-making practices enable Mezirow's confrontation and replacement stages, leading to changed behavior and thinking. Thus, transformative learning theory, with respect to the $\mathrm{GC}$, is linked to formative assessment. 


\section{Experiential Learning}

Kolb's (1984) theory of experiential learning, another example of intentional learning, is frequently cited in research on intercultural competence and global leadership development (e.g., Ng, Van Dyne \& Ang, 2009; Yamazaki, \& Keyes, 2017; Osland, et al., 2019). The theory describes four learning modes that comprise the learning cycle -- Concrete Experience, Reflective Observation, Abstract Conceptualization, and Active Experimentation. According to Kolb (1984), experiential learning is an integrative process that can begin in any part of the learning cycle. Because knowledge is more complete when all four modes are employed, this framework and "teaching around the cycle" is the basis for GC competency modules, simulations, and project-based learning activities. When students reflect upon their concrete experiences in the GC and test new behaviors, this serves as another example of formative assessment.

\section{Cognitive Behavior Therapy}

Cognitive Behavior Therapy (CBT) methodology, a leading clinical therapy, is designed to successfully change human behavior, using the following characteristics: 1) clearly stating the main goal is for people to "learn new behavioral, interpersonal, cognitive and emotionalregulation skills"; (2) placing responsibility for developing self-awareness regarding cognitions, behavior, and subsequent competency developing on the individual; and 3) operating with a clear, limited timeframe (Meichenbaum, 1986, p. 347). CBT forms the foundation of the Personal Development Plan (PDP) utilized in the GC. The PDP assignment focuses on feasible behavioral goals chosen by individuals who are then held accountable for accomplishing them and reporting on their progress throughout the course. Students can modify and improve their action plans that are not working. They write a final report on this process that includes lessons learned. Thus, the CBT-based PDP process is another example of formative assessment designed into the GC.

In sum, the conceptual foundations of the GC all encourage goal-oriented, self-directed intentional learning (Bereiter \& Scardmalia, 1989) involving some type of formative assessment. Students, rather than instructors, bear the primary responsibility for intentional learning, which was one of the Liberal Education and America's Promise (LEAP) report's recommendations for a more globalized $21^{\text {st }}$ century education (AAC\&U, 2007).

\section{Pedagogical Application in a Glocal Setting}

Within international education, there has been a slight but important shift in alternatives or additions to study abroad in recent years. The concept and practice of internationalizing universities, "the process of integrating an international, intercultural, or global dimension into the purpose, functions or delivery of post-secondary education" (Knight, 2004, p. 11), has gained popularity in recent years. Europe's internationalisation@home movement, for instance, calls for "the purposeful integration of international and intercultural dimensions into the formal and informal curriculum for all students within domestic learning environments” (Beelen \& Jones, 2015, p. 59). Reseigh Long (1997) created an experiential course for language acquisition that took advantage of university and community resources while Ha-Brookshire and Stoll (2009) suggested using a 
'live reporter' who, as a native in a foreign country, aids students in a domestic classroom to do primary and secondary marketing research as an alternative to study abroad. Similarly, Howard and Gunter (2017) described the use of web conferencing to allow U.S. students to participate in a health management course in Brazil. The study abroad alternative most closely related to building intercultural effectiveness (Soria \& Troisi, 2014) found that students at nine large U.S. universities who completed international courses, participated in campus cocurricular activities and interacted with international students reportedly developed an equal or greater amount of global international and intercultural competencies than study abroad students.

In addition to study abroad alternatives, efforts to internationalize higher education led to the concept of glocalization, which does not necessarily involve leaving one's campus to visit a foreign country (Francois, 2015). Therefore, the accessibility and potential reach and focus of glocalization tend to be broader. "Glocalization focuses on enhancing the quality of learning for local and global learner cohorts through mutual understanding and shared values at a deep level of academic and social engagement” (Patel, 2017, 1). It incorporates local perspectives into global education, often by focusing on the dialectics of global-local political and socio-economic issues and structural inequities in addition to building intercultural competence (Robertson, 1995; Patel \& Lynch, 2013; Francois, 2015; Patel, 2017).

To our best knowledge, there have been no other pedagogical course design attempts that do not involve study abroad but instead rely on a glocal approach in response to the gaps and limitations in study abroad programs. Furthermore, we found no course designs that utilize assessment as a method of learning as described in the literature (Acheson et al., 2020; Rowe, 2012). To fill this gap, the study results reported here are guided by two research questions.

Within a glocal course with embedded formative and summative assessments:

1. Can students become more interculturally effective in a glocal classroom setting without leaving the country?

2. Do students who participate in this classroom assessment obtain similar intercultural effectiveness results as students who have studied abroad?

The following section describes an effective classroom pedagogy that has been shown to enhance intercultural effectiveness in a setting that aims to replicate the cross-cultural setting of study abroad, with the help of assessment as learning and formative assessment strategies.

\section{Method}

\section{Course Design}

The semester-long course was delivered at a public, urban university in the western United States that offers numerous co-curricular cultural events and study abroad programs with varying degrees of impact. Many students have working class backgrounds and are the first in their families to attend university. Despite the availability of scholarships, many cannot take advantage of study abroad opportunities due to family or work responsibilities. Therefore, 
the GC course provides an opportunity for students to acquire intercultural competencies without having to travel.

The GC course is an elective in various concentrations but is required only for a handful of students minoring in Global Leadership \& Innovation. Classes were held weekly for a total of 165 minutes over a 15-week semester. Each class session was divided into two teaching periods of 75 minutes each, with a 15-minute break. After the first day of class, students were sent links to complete the Intercultural Effectiveness Scale (IES) assessment, which was due on the third week of class. At that time, the assessment was explained and debriefed in class; in pairs, students began discussing potential action plans based on their results. Shortly thereafter, students submitted a Personal Development Plan (PDP) focused on the specific IES dimension they wished to develop. See Appendix A for a description of the PDP assignment.

Students were assigned readings throughout the course that were due prior to the upcoming class session. Each class meeting began with a brief content-related segment on the readings that often began with content quizzes, a brief lecture, topic discussions, and relevant video content. The majority of the course time was devoted to simulations/experiential exercises, which were meticulously designed to replicate in a domestic setting the international experiences (IEs) and demands that confront actual global leaders according to research (Osland, et al., 2012; Osland, et al., 2013). In this regard, the classroom became a global lab where students were immersed into a "foreign" setting that needed to be successfully navigated toward some predesignated outcome (i.e., an understanding of the other, a decoding of the simulated culture, code-switching to adapt to another culture, a win-win solution, etc.). At the end of most exercises, the instructor led a thorough debriefing that included discussion and reflection. The simulations became more sophisticated and challenging as the course progressed and included rubrics for multi-rater feedback to students from 1) the instructor, 2) peers, and 3) self. In the debriefing, students were asked to identify key personal take-aways that they could use going forward to become more interculturally effective. Thus, students received extensive performance feedback, from others and from themselves, to enable their development of intercultural competencies. The course is scaffolded in terms of skill demands as well as the increasing difficulty of simulations, feedback rubrics, and reflections whose purpose is ongoing formative assessment that triggers the development of metacognition and intercultural skills (Morris et al, 2019). In addition to specific skills taught in each class, the GC also had an overarching rubric for the entire course consisting of key global leadership competencies: active listening skills; being non-judgmental; connecting and finding common ground; accurately reading cues and decoding cultural behavior; appropriately adapting communication styles and behaviors (code-switching); tolerating ambiguity; handling stress; and bridging cultural differences to obtain a positive outcome. Students receive this rubric in the beginning of the course, noting that these competencies will be tested on the behavioral final exam. While a full description of the simulations is beyond the scope of this paper, Table 1 lists the course activities and simulations along with their learning objectives and the type of assessment they incorporate. See Appendix B for simulation references. 


\section{Table 1. GC Activities, Learning Objectives and Types of Assessment}

\begin{tabular}{|c|c|}
\hline GC ACTIVITIES* & LEARNING OBJECTIVES AND ASSESSMENT TYPES** \\
\hline $\begin{array}{l}\text { Personal Assessment Instru- } \\
\text { ments \& PDP (self-awareness } \\
\text { \& intercultural effectiveness) }\end{array}$ & $\begin{array}{l}\text { Reflect on strengths and weaknesses (AaL). Create personal development plans to increase competencies, provide } \\
\text { weekly progress reports that receive instructor feedback/coaching (FA), and write a final report on lessons learned. } \\
(\mathbf{A o L})\end{array}$ \\
\hline $\begin{array}{l}\text { BARNGA (intercultural } \\
\text { effectiveness) }\end{array}$ & $\begin{array}{l}\text { Experience and become aware of personal reactions to the uncertainty, ambiguity and stress of foreign norms. } \\
\text { Recognize internal and external cultural attributions and acquire shared language to describe and recognize } \\
\text { common cultural strategies and their impact and appropriate use. (FA) }\end{array}$ \\
\hline $\begin{array}{l}\text { BAFA BAFA } \\
\text { (cultural entry) }\end{array}$ & $\begin{array}{l}\text { Learn to decode cultural differences and adapt by code-switching Recognize personal reactions and effective } \\
\text { intercultural behavior in the cultural entry process. Recognize the impact of describing, interpreting or evaluating } \\
\text { cultural behavior and understanding internal cultural logics. (AaL \& FA) }\end{array}$ \\
\hline $\begin{array}{l}\text { ECOTONOS } \\
\text { (multicultural teams) }\end{array}$ & $\begin{array}{l}\text { Practice cultural observation, decoding and code-switching. Understand the impact of cultural values and team } \\
\text { composition. Recognize effective intercultural strategies and their impact. (AaL \& FA) }\end{array}$ \\
\hline $\begin{array}{l}\text { Cultural Observation Report } \\
\text { (global mindset \& cultural entry) }\end{array}$ & $\begin{array}{l}\text { Closely observe a different culture using ethnographic guide. Connect with stranger cultural informants to clarify } \\
\text { observations and practice interviewing skills. (FA) Submit written observations, reactions, reflections, and an action } \\
\text { step to improve cultural entry skills. (AaL \& AoL) }\end{array}$ \\
\hline $\begin{array}{l}\text { THE OWL (intercultural } \\
\text { communication) }\end{array}$ & $\begin{array}{l}\text { Test decoding and code-switching skills. Recognize effective strategies for relationship building and bridging } \\
\text { extreme language difficulties. Practice observing and giving feedback. (AaL \& FA). }\end{array}$ \\
\hline $\begin{array}{l}\text { STAR TREK video test (int. } \\
\text { communication) }\end{array}$ & $\begin{array}{l}\text { Decode unknown language and culture using observation skills. Identify hypotheses and evidence to support } \\
\text { communication analysis. Recognize effective/ineffective intercultural communication. (AoL) }\end{array}$ \\
\hline $\begin{array}{l}\text { DAIMLER } \\
\text { (multicultural teams) }\end{array}$ & $\begin{array}{l}\text { Practice advanced observation and feedback skills to critique multicultural team leadership. Learn to give difficult } \\
\text { feedback and recognize intercultural effectiveness. (AaL \& FA) }\end{array}$ \\
\hline $\begin{array}{l}\text { ARACRUZ CELLULOSE } \\
\text { (stakeholder dialogue) }\end{array}$ & Practice, observe and critique stakeholder dialogue skills in heterogeneous teams. (AaL \& FA) \\
\hline $\begin{array}{l}\text { Social Innovation Project } \\
\text { (innovation, design thinking, } \\
\text { teams) }\end{array}$ & Demonstrate multicultural teamwork while researching and creating a social innovation solution (AaL, AoL \& FA) \\
\hline $\begin{array}{l}\text { ALPHA BETA (GC compe- tencies } \\
\text { in negotiation) }\end{array}$ & $\begin{array}{l}\text { Demonstrate in this behavioral exam the critical thinking and GC competencies required of global leaders. (AoL \& } \\
\text { FA) }\end{array}$ \\
\hline
\end{tabular}

*Activities are simulations unless otherwise specified

** Forms of Assessment: $\mathbf{A a L}=$ Assessment as learning; $\mathbf{A o L}=$ Assessment of learning; $\mathbf{F A}=$ Formative assessment 
At the end of the 15-week course, students were given a post IES assessment and asked to write a final report on the PDP process that encouraged them to reflect upon the process and their progress and to compare and explain their pre- and post-test results. They were also asked to describe what they had learned during the process and how these lessons might transfer to future intercultural settings and their career. See Appendix A for the Final PDP Report Instructions.

\section{Measures}

The Intercultural Effectiveness Scale ${ }^{1}$ (IES) (Mendenhall, et al., 2008) contains 60 items used to measure three factors consisting of two dimensions: Continuous Learning (SelfAwareness and Exploration); Interpersonal Engagement (World Orientation and Relationship Development); and Hardiness (Positive Regard and Emotional Resilience). Each dimension is defined below with Cronbach’s alpha reported.

Self-Awareness "refers to the degree to which people are aware of: 1) their strengths and weaknesses in interpersonal skills, 2) their own philosophies and values, 3) how past experiences have helped shape them into who they are as a person, and 4) the impact their values and behavior have on relationships with others" (alpha = .76) (Mendenhall, et al., 2008, p. 7).

Exploration "reflects openness towards, and an active pursuit of understanding ideas, values, norms, situations, and behaviors that are new and different. It involves the willingness to seek to understand the underlying reasons for cultural differences and to avoid stereotyping people from other cultures” (alpha = .82) (Mendenhall, et al., 2008, p. 8).

World Orientation "measures the degree to which one is interested in and seeks to actively learn about other cultures and the people that live in them” (alpha=.84) (Mendenhall, et al., 2008, p. 9).

Relationship Development "refers to the degree to which people have a desire and willingness to initiate and maintain relationships with people from other cultures" (alpha $=.80$ ) (Mendenhall, et al., 2008, p. 9).

Positive Regard "refers to the predisposition to view other cultures and people from those cultures from a positive perspective. This reflects a tendency to avoid negative stereotypes in favor of a more positive view of human nature" (alpha $=.79$ ) (Mendenhall, et al., 2008, p. 11).

Emotional Resilience "refers to the extent to which a person has emotional strength and resilience to cope with challenging cross-cultural situations” (alpha $=.81$ ) (Mendenhall, et al., 2008, p. 12).

A demographic survey was administered online at the beginning of the course (see Table 2). The term bicultural describes a state of having or inheriting two or more cultures (e.g., one of an ethnic heritage and one of culture lived in) or two or more ethnic traditions. To measure bicultural status, students either responded negatively to the question, "Do you come

\footnotetext{
${ }^{1}$ The original names of the Interpersonal Engagement dimensions (Global Mindset and Relationship Interest) were subsequently modified by the Kozai Group to provide more clarity.
} 
from a bicultural family?" or chose one of the following descriptions: a) "Yes, my parents are of two (or more) countries;" b) "Yes, I grew up in more than one country;" and c) "Yes, my parents are from one culture, and I grew up in a different culture." These responses were then coded to yes.

\section{Sample}

The data was collected across three semesters with three instructors (one instructor teaching three classes and the other two instructors teaching one course each). The sample yielded $n=148$ responses. Three participants, however, failed to complete the post-test and were eliminated, resulting in $n=145$ paired pre- and post-test measurements. See Table 2 for demographic data of the sample.

\section{Table 2. Demographics of Students}

\begin{tabular}{|l|c|c|}
\hline & $n$ & $\%$ \\
\hline Gender & & \\
\hline Females & 67 & 46.2 \\
\hline Males & 78 & 53.8 \\
\hline Age & 2 & 1.4 \\
\hline under 20 years old & 131 & 90.3 \\
\hline $20-29$ & 11 & 7.5 \\
\hline $30-39$ & 1 & 0.8 \\
\hline $40-49$ & & \\
\hline Study Abroad & 34 & 23.4 \\
\hline Yes & 111 & 76.6 \\
\hline No & & \\
\hline Ethnicity & 54 & 37.2 \\
\hline Asian & 35 & 24.1 \\
\hline Hispanic/Latinx & 41 & 28.2 \\
\hline White & 5 & 3.4 \\
\hline Black/African American & 6 & 4.1 \\
\hline Pacific Islander & 1 & 0.8 \\
\hline American Indian & 3 & 1.9 \\
\hline Not reported & & \\
\hline Citizenship & 102 & 70.3 \\
\hline U.S Citizenship & 33 & 22.7 \\
\hline Other than U.S. & 9 & 6.2 \\
\hline $\begin{array}{l}\text { Dual (U.S. \& other } \\
\text { country) }\end{array}$ & 1 & 0.8 \\
\hline Not reported & 101 & 69.7 \\
\hline Bicultural status & 44 & 30.3 \\
\hline Yes & & \\
\hline No & & \\
\hline & & \\
\hline
\end{tabular}

\section{Results}

Data were analyzed using SPSS. Descriptive statistics were generated for all the variables. See Table 3 for a review of the results. We first conducted a one-way ANOVA to rule out any possibility of unexpected differences based on the teaching styles or global leadership 
background of the three instructors. No differences existed among the instructors in the post IES assessments. Therefore, any differences found would relate to the individual students and their experiences within the course.

Next, we investigated whether there were significant correlations between the IES measurements and the demographics of the sample. Gender had a significant relationship with the pre and post Self-Awareness measurement and the pre and post Emotional Resilience measurement. For students who had studied abroad, both World Orientation and Relationship development was significantly higher. Unlike some prior study abroad studies focused on global leadership development that utilized the pre and post IES measure (e.g., Quirk \& Gustafson, 2019), no significant relationships were found between any of the measurements and students who self-identified as bicultural. See Table 3 (next page) for all correlations. 


\section{Table 3. Means, Standard Deviations, and Correlations}

\begin{tabular}{|c|c|c|c|c|c|c|c|c|c|c|c|c|c|c|c|c|c|c|}
\hline & $M$ & $S D$ & 1 & 2 & 3 & 4 & 5 & 6 & 7 & 8 & 9 & 10 & 11 & 12 & 13 & 14 & 15 & 16 \\
\hline 1. SA(pre) & 3.94 & .45 & & & & & & & & & & & & & & & & \\
\hline 2. Explr (pre) & 4.31 & .41 & $.65 * \star$ & & & & & & & & & & & & & & & \\
\hline 3. WO (pre) & 3.08 & .81 & $.34 * \star$ & $.49 * *$ & & & & & & & & & & & & & & \\
\hline 4. RDev (pre) & 4.07 & .55 & $.29 * \star$ & $.55 * \star$ & $.37 * \star$ & & & & & & & & & & & & & \\
\hline 5. Preg(pre) & 3.31 & .58 & .05 & $.23 * *$ & -.02 & $.43 * *$ & & & & & & & & & & & & \\
\hline 6. Eres(pre) & 3.37 & .66 & $.36 * \star$ & $.36 * *$ & .14 & $.39 * *$ & $.37 * *$ & & & & & & & & & & & \\
\hline 7. IES (pre) & 3.69 & .38 & $.62 * *$ & $.78 * *$ & $.64 * *$ & $.76 * *$ & $.51 * *$ & $.67 * *$ & & & & & & & & & & \\
\hline 8. SA (pst) & 4.24 & .44 & $.46 * \star$ & $.32 * \star$ & .12 & $.27 * \star$ & .03 & $.25 * \star$ & $.34 * *$ & & & & & & & & & \\
\hline 9. Explr (pst) & 4.46 & .37 & $.42 * *$ & $.53 * *$ & $.29 * *$ & $.47 * *$ & .15 & $.29 * *$ & $.52 * \star$ & $.68 * *$ & & & & & & & & \\
\hline 10. WO (pst) & 3.56 & .76 & $.26 * \star$ & $.38 * *$ & $.66 * *$ & $.31 * \star$ & -.04 & .14 & $.45 * *$ & $.43 * *$ & $.50 * *$ & & & & & & & \\
\hline 11.Rdev(pst) & 4.25 & .54 & .16 & $.31 * *$ & $.21 *$ & $.71 * \star$ & $.33 * *$ & $.24 * *$ & $.49 * *$ & $.40 * *$ & $.60 * \star$ & $.38 * *$ & & & & & & \\
\hline 12.Preg(pst) & 3.49 & .65 & .07 & .06 & -.03 & $.25 * \star$ & $.48 * *$ & $.18^{*}$ & $.25 * *$ & .10 & $.20 *$ & .04 & $.46 * *$ & & & & & \\
\hline 13.Eres(pst) & 3.66 & .72 & $.26 * *$ & $.22 *$ & .05 & $.25 * \star$ & $.20 *$ & $.66 * \star$ & $.41 * *$ & $.45 *$ & $.41 * \star$ & $.23 * *$ & $.40 * *$ & $.44 * *$ & & & & \\
\hline 14. IES (pst) & 3.95 & .39 & $.37 * *$ & $.41 * *$ & $.33 * *$ & $.53 * *$ & $.28 * *$ & $.44 * *$ & $.59 * \star$ & $.68 * *$ & $.76 * \star$ & .64 ** & $.76 * \star$ & $.57 * *$ & $.73 * \star$ & & & \\
\hline 15. Gender & -- & -- & $.26 * \star$ & .12 & .06 & -.09 & -.06 & $.19 *$ & .11 & $.18 *$ & .10 & .15 & -.04 & -.11 & $.20 *$ & .13 & & \\
\hline 16. St Abroad & -- & -- & -.04 & .12 & $.25 * *$ & $.19 *$ & -.05 & -.02 & .13 & -.03 & .15 & $.22 * *$ & $.17 *$ & -.08 & -.06 & .09 & -.08 & \\
\hline 17. Bi-Cult & -- & -- & -.13 & .06 & .05 & .09 & -.07 & -.05 & -.01 & -.01 & .07 & .12 & .06 & -.14 & -.03 & .01 & -.16 & -.06 \\
\hline
\end{tabular}

Gender (0=female; $1=$ male); Study Abroad in College (0=no, 1=yes); Bi-Cultural (0=no, 1=yes)

Correlation is significant at ** $p<.01 ; * p<.05$

Third, we conducted a $t$ test for paired-samples to see if there were significant changes between the pre and post IES test. As shown in Table 4 (next page), all the IES measurements changed significantly from Time 1(beginning of the course) and Time 2 (end of the course). This provides an affirmative answer to the first research question asking whether the GC Assessment Center's pedagogical approach increased the intercultural effectiveness of the students.

Next, to test our second research question, "Do students who participate in this classroom assessment yield similar results of intercultural effectiveness to students who have studied abroad?”, we conducted a one-way ANOVA. There were 34 students (23.4\%) in the sample who had participated in a study abroad in college. We first compared the pretest IES results of the study abroad students with those of the non-study abroad students. Only two measurements, world orientation and relationship development, were significantly different between these groups. The ANOVA was significant, $F(1,143)=9.26$, $p=.003$, for world orientation. The means and standard deviations are reported in Table 5 (next page). The ANOVA was also significant for relationship development, $F(1,143)=5.10, p=.03$. The means and standard deviations are reported in Table 6 (next page). 
Table 4. Results of Paired-Samples $T$ Test $(n=145)$

\begin{tabular}{|c|c|c|c|c|}
\hline Variable & $\begin{array}{c}\text { (Mean, SD) } \\
\text { Pretest }\end{array}$ & $\begin{array}{c}\text { (Mean, SD) } \\
\text { Post-test }\end{array}$ & $T$ Test & Effect size \\
\hline Self-awareness & $\begin{array}{l}M=3.94 ; \\
S D=.454\end{array}$ & $\begin{array}{l}M=4.24 ; \\
S D=.441\end{array}$ & $t(144)=7.72 ; p=.000)$ & .66 \\
\hline Exploration & $\begin{array}{l}M=4.31 ; \\
S D=.411\end{array}$ & $\begin{array}{l}M=4.46 ; \\
S D=.376\end{array}$ & $t(144)=4.45 ; p=.000)$ & .34 \\
\hline Global Mindset & $\begin{array}{l}M=3.09 ; \\
S D=.807\end{array}$ & $\begin{array}{l}M=3.57 \\
S D=.756\end{array}$ & $t(144)=8.99 ; p=.000)$ & .59 \\
\hline $\begin{array}{l}\text { Relationship } \\
\text { interest }\end{array}$ & $\begin{array}{l}M=4.07 ; \\
S D=.555\end{array}$ & $\begin{array}{l}M=4.26 \\
S D=.539\end{array}$ & $t(144)=5.39 ; p=.000)$ & .34 \\
\hline Positive regard & $\begin{array}{l}M=3.32 ; \\
S D=.582\end{array}$ & $\begin{array}{l}M=3.49 \\
S D=.649\end{array}$ & $t(144)=3.52 ; p=.001)$ & .31 \\
\hline $\begin{array}{l}\text { Emotional } \\
\text { resilience }\end{array}$ & $\begin{array}{l}M=3.37 ; \\
S D=.665\end{array}$ & $\begin{array}{l}M=3.66 \\
S D=.716\end{array}$ & $t(144)=6.08 ; p=.000)$ & .44 \\
\hline Overall IES & $\begin{array}{l}M=3.69 \\
S D=.381\end{array}$ & $\begin{array}{l}M=3.95 \\
S D=.394\end{array}$ & $t(144)=8.91 ; p=.000)$ & .68 \\
\hline
\end{tabular}

Table 5. Differences in World Orientation (Pretest) between Students Who Had Studied Abroad ( $n=34)$ and Students Who Had Not Studied Abroad ( $n=111)$

\begin{tabular}{llr}
\hline World Orientation & $M$ & $S D$ \\
\hline Study Abroad Participant (Pretest) & 3.44 & 0.82 \\
Did not Study Aboard (Post-test) & 2.97 & 0.77 \\
\hline
\end{tabular}

Table 6. Differences in Relationship Development (Pretest) between Students Who Had Studied Abroad ( $n=34)$ and Students Who Had Not Studied Abroad $(n=111)$ (Post-test)

\begin{tabular}{llr}
\hline Relationship Development & $M$ & $S D$ \\
\hline Study Abroad Participant (Pretest) & 4.25 & 0.55 \\
Did not Study Aboard (Post-test) & 4.01 & 0.54 \\
\hline
\end{tabular}

Next, we compared the IES measurements (pretest) of students who had participated in study abroad with the IES measurements (post-test) of the students who had not studied abroad. With this test, we wanted to examine if the students who had participated only in the course could be as interculturally effective as students who had studied abroad. The ANOVA between the groups was not significant for any of the measurements. Therefore, the pretest results of the students who had studied abroad were not significantly different than the post-test results of the students without study abroad experience, as shown in Figure 1. This appears to provide an affirmative answer to the question of whether students in a glocal classroom setting can approximate the intercultural effectiveness acquired abroad. Post-test results for students with study abroad experience also improved, so there is still a significant difference between the two groups at Time 2, suggesting that study abroad provides an enduring advantage, unless students attracted to study abroad have higher intercultural effectiveness profiles than those who are not interested in international education. It is noteworthy that the non-study abroad group were at least able to match the study abroad advantage found in the beginning of the course. 
Figure 1. Study Abroad ( $n=34)$ versus Non-Study Abroad Students ( $n=111)$

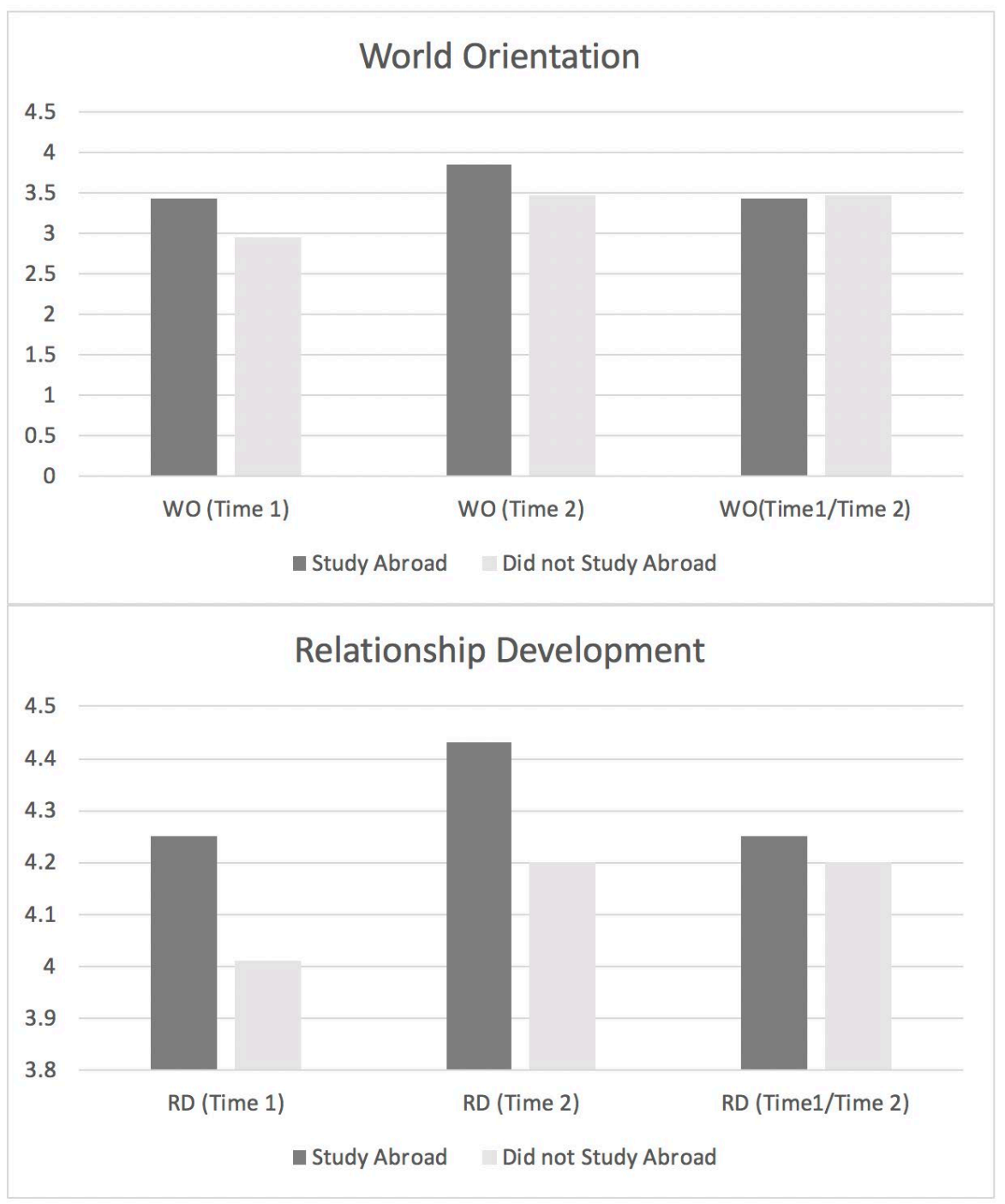

\section{Post-Hoc Analysis}

While the overall IES results increased between the start and end of the course, over $64 \%(n=93)$ of the students rated at least one IES dimension lower in the post-test. See Table 7 for the percentages. This pattern will be addressed in the discussion section.

\section{Table 7. Number of measurements that were lower post-test $(n=93)$}

\begin{tabular}{|c|c|}
\hline $\begin{array}{c}\text { Number of measurements that were lower post- } \\
\text { test }\end{array}$ & Percentage of students \\
\hline 1 & $28 \%(n=26)$ \\
\hline 2 & $32 \%(n=30)$ \\
\hline 3 & $13 \%(n=12)$ \\
\hline 4 & $11 \%(n=10)$ \\
\hline 5 & $15 \%(n=14)$ \\
\hline 6 & $0 \%(n=0)$ \\
\hline 7 & $1 \%(n=1)$ \\
\hline
\end{tabular}




\section{Discussion}

This study of a carefully designed glocal course that relies on learning as assessment makes significant contributions in several areas, which are even more important given the current restrictions necessitated by the COVID-19 pandemic. First, the data indicate that it is possible to approximate in a glocal classroom some dimensions of intercultural effectiveness attained by students with actual study abroad experience. At the beginning of the course, the only significant difference between students who had studied abroad and those who had not were higher scores in World Orientation and Relationship Development for the former group. Post-test results for the latter group, those without study abroad experience, indicated that this difference was not significant after participating in the GC, as shown in Figure 1. While there is admittedly much more to an international experience than a domestic classroom can capture, the GC does a good job of replication via careful design and leveraging the diversity in the classroom.

It is noteworthy that the World Orientation dimension mentioned above also played a figural role in a recent large longitudinal study on the causal link between international experience and intercultural effectiveness (Berdrow, et al., 2020). World Orientation (termed global mindset in their study) was the only IES dimension that increased as a result of an international experience, and higher World Orientation scores resulted from specific respondent behaviors (motivated to do study abroad to gain access to and make connections with family, friends or a partner; lived with a non-American roommate; and visited local sites).

Berdrow and her colleagues (2020) also found that four IES dimensions (SelfAwareness, Exploration, Global Mindset, and Emotional Resilience) increased between the pre and post measures in the sophomore and senior year in students without an international experience. This indicates that university students can develop some degree of intercultural effectiveness in non-intentional ways from the college experience or the maturation process. However, the rapid increase over a 15-week semester manifested in the GC is a more certain method for developing intercultural effectiveness, which brings us to the study's second major contribution. At the aggregate level, all IES dimensions improved significantly in a relatively short time period within a course structure. We hypothesize that this is partly due to the high degree of control over a classroom experience with a set curriculum.

While the aggregated post-test results increased, not all students reported change in positive directions for every dimension. The majority of the sample (64\%) had at least one dimension with a lower post-test result. Fortunately, student reflections from the final PDP reports helped explain this phenomenon. That data suggests that pre and post assessment also encourages students to realize that they might not be as strong in an area as they assumed prior to actual experience. Howell's (1982) model of competence may provide an explanation for lower post-test results. The model has four quadrants, ranging clockwise starting at the lower left from unconscious incompetence (you do not know what you do not know; lack of awareness) to conscious incompetence (you realize you are not as expert as you thought you were), to conscious competence (you are learning, perhaps in fits and starts, to become more competent), and finally unconscious competence (you have become so expert that conscious attention is not required for competence). If students were in the unconscious incompetence stage when they first took the IES, a lower post-test result may 
indicate their progression to the conscious incompetence stage, which is mentioned in many final PDP reports. In several instances, students did not realize how complex it was to work across cultures until confronted with realistic simulations or multicultural experiences. Thus, whenever quantitative instruments are used to assess intercultural learning over time, they should be buttressed by qualitative measures to convey the full story. This is another example of the importance of assessment as learning.

Like study abroad experiences, course sections can vary widely. One likely source of variance are the instructors. While the GC instructors varied on several dimensions global leadership background, global experience, experience teaching the course, years of teaching experience, age and gender - there were no significant differences in the student IES measures from different sections. Because the GC is part of an ongoing research study on best practices in global leadership development, instructors were carefully selected and agreed to teach experientially and follow the set framework of the course. We contend that the similarity of student outcomes and absence of differential instructor impact seems to indicate that the pedagogy and structure of utilizing ongoing formative formal and informal feedback, that is assessment as learning in the course may be more important than individual teaching.

\section{Research Limitations and Future Directions}

While this study emphasizes the importance of assessment as learning and contributes some interesting findings, it is not without limitations. First, the data is correlational and the findings cannot be used to infer causality. However, given the promising nature of the findings and their potential usefulness, future studies could extend this work by employing control groups. Although the reflections in their final Personal Development Plan Report attribute some improvement to their personal efforts and the GC experience, perhaps improvement also results from typical daily student interactions on a highly diverse campus. Two control groups would improve the study - one composed of students who are not studying global leadership and one studying global leadership in a traditional classroom setting. A larger sample of students in different types of locations and utilizing enough types and sources of data would permit even stronger conclusions about causal relationships.

Second, the same diversity mentioned previously might also limit the generalizability of these findings. In a less diverse university and region, students might be less willing and able to recognize the importance of developing intercultural effectiveness and its link to career success. Furthermore, constant exposure to other culture and ethnic groups might have predisposed the sample in this study to greater acquisition of intercultural effectiveness.

Third, the study is based on pre and post single source data consisting of self-reports. It would be improved by second-party observations of intercultural effectiveness in students.

Fourth, while this study measured a key competency with a rigorous instrument (for a comparison of instruments, see Bird \& Stevens, 2018), both study abroad programs and glocal classrooms are characterized by greater complexity, which warrants further investigation and comparisons. The findings of the current study are encouraging, but they should not be used to argue that glocal classrooms constitute a 1:1 replacement of international education and cultural immersion programs. Students with study abroad 
experience were still significantly higher than students without study abroad experience in Time 2. Further research could explore if prior international experience predisposes university students to take fuller advantage of subsequent training, and, if so, why? Conversely, does the GC experience prepare students to take fuller advantage subsequent study abroad programs? And, returning to a more basic question, are students with higher levels of intercultural competence more motivated to seek out study abroad programs?

Finally, analysis regarding the types of study abroad experiences by students in a glocal classroom call for future research. While we did not collect specific types of study abroad experiences (low, moderate or high impact), a more robust data collection could provide further insight when comparing students who only participated in the glocal classroom versus students who participated in different types of study abroad experiences.

The GC was designed with two goals in mind - to create a simulated global environment similar to that experienced by global leaders and to incorporate best practices in global leadership development. As the study findings suggest, however, the GC experience also serves as an effective alternative to an international experience with respect to improving the world orientation and relationship development of students. This is not surprising given the theoretical foundations the GC shares with the study abroad research (e.g., experiential learning, transformative learning) and the similarity of learning outcomes. This led us to look at other commonalities with the study abroad literature and with best practices in particular. The following paragraphs lay the groundwork for future research on glocal classrooms that benefit from the international experience literature regarding engagement with diverse students and mediated learning.

Relationship-building with diverse others may share some similarity to the study abroad finding that students who choose to engage with someone in the host culture benefit more (Vande Berg, et al., 2012) and are more likely to develop a global mindset, particularly if they are intentional in their choices, interactions and behaviors (Berdrow, et al., 2020). Team formation in the GC is based on the goal of maximizing diversity, thereby forcing students to engage with non-friends, other cultures and ethnic groups, majors, colleges, age groups, and genders. Teams work outside of class on their project and sit together at the beginning of each class period until divided into random groups for simulations. As a result, they are exposed to everyone in class and develop close relationships with a greater number of students in the classroom learning community than one observes in lecture classes. Future research could study the intention to learn and the willingness to develop diverse relationships in glocal classrooms.

Another best practice identified in study abroad programs is mediated learning by experienced faculty or trip leaders, which is more likely to ensure that students make sense of their cultural experiences in a positive and accurate manner (Vande Berg et al., 2012). One aspect of the GC corollary is skillful instructor facilitation when debriefing experiential exercises and when responding to student assignments and progress reports. Both involve a form of personal coaching and asking questions that prompt a more advanced form of sensemaking. The second GC corollary to mediated learning is the heavy reliance on student feedback, which is purposefully encouraged and developed during the course. Future research on the skills needed to mediate learning in glocal programs in both instructors and fellow students and their impact could be helpful. 
At the university in question, more advanced graduate-level hybrid GC global leadership courses have been taught successfully for years to classes consisting of both face-to-face students and distance students located inside/outside the United States. In the past year, however, GC courses at both levels were taught virtually due to COVID restrictions, raising the research question of whether hands-on, high-touch teaching can fully transfer to a fully virtual setting. To date, the most pertinent resource contrasts cultural immersion experiences with an online global leadership course that successfully utilized the PDP process (Mendenhall, 2019). Essays like this are very helpful, but empirical research is also needed on the impact of virtual classrooms on global skill-building courses.

On a different note, anecdotal reports suggest that faculty led programs benefited from 2-4 days of GC predeparture training, which is a shorter, condensed version of the GC course. Faculty reported that a richer international experience resulted from the basic intercultural competency and targeted culture training, the creation of a strong learning community, and the assessments taken in GC predeparture training, as well as the related PDPs students worked on during the international experience itself. It would be interesting to test whether study abroad programs benefit from the GC approach to predeparture training and assessment.

At present, study abroad programs, as well as face-to-face teaching, are blocked by Covid-19 restrictions. However, we are also living in a time when "people have found more and more ways to distance themselves from each other, and to protect their own understanding of the world" (Berdrow et al, 2020, p. 1). Cultural immersion admittedly offers numerous benefits for open-minded students, but this study suggests another option when study abroad is not possible or in combination with study abroad - a glocal classroom with a strong focus on assessment that provides awareness into cognition and effective intercultural behaviors through ongoing monitoring and feedback (Acheson, et al., 2020; Rowe, 2012). Hence, our proposed pedagogy utilizes assessment as a learning tool to provoke self-awareness, as well as ongoing formative assessment in the form of weekly feedback (peer and instructor), self-feedback, reflection, and the summative assessment in a final PDP report to inspire the development of metacognition and intercultural skills (Morris et al, 2019). In this way, we too can avoid the pitfalls of intercultural communication scholar Milton Bennett's famous warning: "Simply because students are in the vicinity of an intercultural learning opportunity does not mean they will have one."

\section{References}

AAC\&U, (2007). College learning for the new global century. Washington, D.C.: Association of American Colleges \& Universities. https://www.aacu.org/sites/default/files/files/LEAP/GlobalCentury final.pdf

Acheson, K., \& Schneider-Bean, S. (2019). Representing the intercultural development continuum as a pendulum: Addressing the lived experiences of intercultural competence development and maintenance. European Journal of Cross-cultural Competence and Management, 5(1), 42. DOI: 10.1504/EJCCM.2019.097826

Acheson, K., Yngve, K. N., Stahl, A., \& Lan, J. (2020). Introduction: Recent research in assessment education abroad. Frontiers: The Interdisciplinary Journal of Study Abroad, 1-6. DOI: https://doi.org/10.36366/frontiers.v32iVirtual.464

Ashford, S. J., \& Tsui, A. S. (1991). Self-regulation for managerial effectiveness: The role of active feedback seeking. Academy of Management Journal, 34(2), 251-280. DOI: 10.2307/256442

Beelen, J., \& Jones, E. (2015). Redefining internationalization at home. In A. Curai, L. Matei, R. Pricopie, J. Salmi \& P. Scott (Eds.), The European higher education area: Between critical reflections and future policies (pp. 67-80). Dordrecht: Springer. 
Bennett, J. (2008). Transformative training: Designing programs for culture learning. In M. A. Moodian (Ed.) Contemporary leadership and intercultural competence: Understanding and utilizing cultural diversity to build successful organizations. (pp. 95-110). Thousand Oaks, CA: Sage.

Berdrow, I., Woolford, S., Skaletsky, M. \& Bird, A. (2020). Intercultural effectiveness: Do international education experiences move the needle? Paper presentation, Academy of International Management Conference, July, 2020.

Bereiter, C., Scardamalia, M. (1989). Intentional learning as a goal of instruction. In L. Resnick (Ed.), Knowing, learning, and instruction: Essays in honor of Robert Glaser (pp. 361-392). Hillsdale, NJ: Lawrence Erlbaum Associates.

Bird, A., \& Stevens, M. J. (2018). Assessing global leadership competencies. In M. E. Mendenhall, J. S. Osland, A. Bird, G. R. Oddou, M. J. Stevens, M. L. Maznevski, \& G. Stahl (Eds.), Global Leadership: Research, Practice and Development (3 $3^{\text {rd }}$ edition, p. 143-176). New York: Routledge.

Bok, D. (2006). Our Underachieving Colleges: A Candid Look at How Much Students Learn and Why They Should Be Learning More. Princeton, NJ: Princeton University Press.

Butler, A. C., Chapman, J. E., Forman, E. M., \& Beck, A. T. 2006. The empirical status of cognitivebehavioral therapy: A review of meta-analysis. Clinical Psychology Review, 26, 17-31. DOI: 10.1016/j.cpr.2005.07.003

Deardorff, D. (2011). Assessing intercultural competence. New Directions for Institutional Research, 149, 65-79. https://doi.org/10.1002/ir.381

Deters, J. (2017). Global leadership talent management: Successful selection of global leadership talents as an integrated process. Bingley, UK: Emerald Publishing Limited.

Francois, E. J. (2015). Building global education with a local perspective: An introduction to glocal higher education. New York: Palgrave MacMillan.

Ha-Brookshire, J. E., \& Stoll, E. (2009). Teaching Global Business Using a Live Reporter in a Foreign Country: An Alternative to Study Abroad. Marketing Education Review, 19(3),17-23, DOI:10.1080/10528008.2009.11489083

Herd, A., Cumberland, Lovely, W., \& Bird, A. (2018). The use of assessment center methodology to develop students' global leadership competencies: A conceptual framework and applied example. Advances in Global Leadership, 11, 175-196.

Howard, W., \& Gunter, G. (2017). Examination of an Innovative Solution for Internationalizing the Curriculum Through Online Study Abroad. Journal of Formative Design in Learning, 1: 3-15. https://doi.org/10.1007/s41686-017-0002-4

Howell, W.S. (1982). The empathic communicator. University of Minnesota: Wadsworth Publishing Company.

Institute of International Education (IIE) (2019). Open Doors 2019 Fast Facts. Retrieved from https://www.iie.org/Research-and-Insights/Open-Doors.

Knight, J. (2004). Internationalization remodeled: Definition, approaches, and rationales. Journal of Studies in International Education, 8(1), 5-31.

Kolb, D. A. (1984). Experiential learning: Experience as the source of learning and development. Englewood Cliffs, NJ: Prentice Hall.

Langer, E. J., \& Moldoveanu, M. (2000). The construct of mindfulness. Journal of Social Issues, 56(1), 1-9. https://doi.org/10.1111/0022-4537.00148

Lokkesmoe, K. J., Kuchinke, K. P., \& Ardichvili, A. (2016). Developing cross-cultural awareness through foreign immersion programs: Implications of university study abroad research for global competency development. European Journal of Training \& Development, 40(3), 155-170. DOI:10.1108/EJTD-07-2014-0048

March, J., \& Simon, H. (1963). Organization. New York: John Wiley.

Meichenbaum, D. (1986). Cognitive behavior modification. In F.H. Kanfer \& A.P. Goldstein (Eds.), Helping people change: A textbook of methods ( $3^{\text {rd }}$ ed.), pp. 346-380. Elmsford, NY: Pergamon Press.

Mendenhall, M. E., Stevens, M. J., Bird, A., Oddou, G., \& Osland, J. S. (2008). Specification of the content domain of the Intercultural Effectiveness Scale. Chesterfield, MO: The Kozai Group. Retrieved from https://www.kozaigroup.com/wp-content/uploads/2015/09/IESTechReport.pdf

Mendenhall, M. E., Arnardottir, A., Oddou, G., Burke, L. (2013). Developing cross-cultural competencies in management education via cognitive-behavior therapy. Academy of Management Learning \& Education, 12(3), 436-451. DOI: 10.5465/amle.2012.0237 
Mendenhall, M. E., Weber, T. J., Arnardottir, A. A., \& Oddou, G. R. (2017). Developing global leadership competencies: A process model. In J. S. Osland, M. Li, \& M. Mendenhall (Eds.), Advances in Global Leadership, 10, 117-146. Emerald Publishing Limited.

Mendenhall, M. E. (2019). Can global leadership be taught online? Advances in Global Leadership, 11, 197-211.

Mezirow, J., \& Associates. (1990). Fostering critical reflection in adulthood: A guide to transformative and emancipatory learning. San Francisco: Jossey-Bass.

Mezirow, J. (1978). Perspective transformation. Adult Education, 28(2), 100-109.

Morris, M. W., Savani, K., \& Fincher, K. (2019). Metacognition fosters cultural learning: Evidence from individual differences and situational prompts. Journal of Personality and Social Psychology: Interpersonal Relations and Group Processes, 116(1), 46-68. https://doi.org/10.1037/pspi0000149

Ng, K. Y, Van Dyne, L., \& Ang, S. (2009). From experience to experiential learning: Cultural intelligence as a learning capability for global leader development. Academy of Management Learning \& Education, 8(4): 511-526. https://doi.org/10.5465/amle.8.4.zqr511

OECD (2005). Formative Assessment: Improving Learning in Secondary Classrooms, OECD Publishing, Paris. Retrieved July 11, 2020 from https://doi.org/10.1787/9789264007413-en.

Osland, J. S., \& Bird, A. (2000). Beyond sophisticated stereotyping: Cultural sensemaking in context. Academy of Management Executive, 14(1), 65-77.

Osland, J. S., Bird, A., \& Oddou, G. (2012). The context of expert global leadership. Advances in Global Leadership, 7, 107-124. https://doi.org/10.1108/S1535-1203(2012)0000007009

Osland, J.S., Dunn-Jensen, L.M., Nam, K-A., Wells, P. (2017). The Global Leadership Advancement Center: Developing Global leadership Expertise in a University Setting. In Advances in Global Leadership, Volume10, (pp. 241-250). Emerald Publishing Limited.

Osland, J.S, Li, M., Petrone, M., \& Mendenhall, M. E. (2019). Global leadership development in the university setting and future directions for advancing global leadership research. In J. Osland, M. E. Mendenhall, \& M. Li (Eds.), Advances in Global Leadership, 11, pp. 347-366. Bingley, UK: Emerald.

Osland, J. S., Oddou, G., Bird, A., \& Osland, A. (2013) Exceptional global leadership as cognitive expertise in the domain of global change. European Journal of International Management, 7(5), 517-534. https://doi.org/10.1504/EJIM.2013.056475

Patel, F., \& Lynch, H. (2013). Glocalization as an alternative to internationalization in higher education: Embedding positive glocal learning perspectives. International Journal of Teaching and Learning in Higher Education, 25(2), 223-230. https://files.eric.ed.gov/fulltext/EJ1016539.pdf

Patel, F. (2017). Deconstructing internationalization: Advocating glocalization in international higher education. Journal of International \& Global Studies, 8(2), 64-82. https://www.lindenwood.edu/files/resources/64-82-deconstructing-internationlization.pdf

Quirk, S. L., \& Gustafson, J. (2019). Developing the next generation of global leaders: Proposing an iterative framework for student global leadership development. Advances in Global Leadership, 11, 215-256.

Reseigh Long, D. (1997). The experiential course: An alternative to study abroad for nontraditional students. Foreign Language Annals, 30(3), 301-310. https://doi.org/10.1111/j.1944-9720.1997.tb02353.x

Robertson, R. (1995). Glocalization: Time-space and homogeneity-heterogeneity. In M. Featherstone, S. Lash, \& R. Robertson (Eds.), Global modernities 25-44. London: Sage.

Rousseau, D., (1995). Psychological contract in Organizations: Understanding written and unwritten agreements. Newbury Park, CA: Sage.

Rowe, J. (2012). Assessment as learning. Retrieved July 10, 2020 from http://etec.ctlt.ubc.ca/510wiki/Assessment as Learning

Schraw, G. (1998). Promoting general metacognitive awareness. Instructional Science, 26(1/2), 113-125.

Shipmann, J. S., Ash, R. A., Carr, L., Hesketh, B., Pearlman, K., Battista, M., Eyde, L. D., Kehoe, J., Prien, E. P., \& Sanchez, J. I. (2000). The practice of competency modeling. Personnel Psychology, 53(3), 703740. . https://doi.org/10.1111/j.1744-6570.2000.tb00220.x

Soria, K. M., \& Troisi, J. (2014). Internationalization at home alternatives to study abroad: Implications for students' development of global, international, and intercultural competencies. Journal of Studies in International Education, 18(3): 261-280. https://doi.org/10.1177/1028315313496572

Ting, Toomey, S., \& Dorjee, T. (2019). Communicating Across Cultures. New York: The Guilford Press. 
Thomas, D. C. (2006). Domain and development of cultural intelligence: The importance of mindfulness. Group and Organizational Management, 31(1), 78-99. DOI: 10.1177/1059601105275266

Vande Berg, M. (2007). Intervening in the learning of U.S. students abroad. Journal of Studies in International Education, 11(3), 392-398.

Vande Berg, M. (2009). Intervening in student learning abroad: A research-based inquiry. Intercultural Education, 20(4), 15-27.

Vande Berg, M., Paige, R. M., \& Lou, K. H. (2012). Student learning abroad: What our students are learning, what they're not, and what we can do about it. Sterling, VA: Stylus Publishing, LLC.

West, C. (2019). Breaking Barriers to Study Abroad. International Educator, 28(4), 30-35. https://www.nafsa.org/ie-magazine/2019/7/1/breaking-barriers-study-abroad

Weurlander, M., Soderberg, M., Scheja, M., Hult, H., \& Wernerson, A. (2012). Exploring formative assessment as a tool for learning: Students' experiences of different methods of formative assessment. Assessment and Evaluation in Higher Education, 37(6), 747-760. https://doi.org/10.1080/02602938.2011.572153

Yamazaki, Y., \& Keyes, D. C. (2017). An experiential approach to cross-cultural learning: A review and integration of competencies for successful expatriate adaptation. Academy of Management Learning \& Education, 3(4), 362-379. DOI: 10.5465/AMLE.2004.15112543

Yorke, M. (2003). Formative assessment in higher education: Moves towards theory and the enhancement of pedagogic practice. Higher Education, 45(4), 477-501.

https://ink.springer.com/article/10.1023/A:1023967026413

\section{Acknowledgments}

The authors want to acknowledge Thomas Shirley for his global leadership teaching contributions and support for this research.

\section{Author Biographies}

Linda M. Dunn-Jensen, Ph.D. is an Assistant Professor of Management at Cal State, Stanislaus. She holds a Ph.D. degree in Organizational Behavior from New York University. She teaches courses in organizational behavior, leadership, and negotiation. Dr. DunnJensen's research and consulting work focuses on organizational citizenship behavior, unconscious bias, and negotiation. Her work has been published in Organization Management Journal, Journal of Management Education, and International Journal of Conflict Management.

Joyce S. Osland, Ph. D. is a senior partner of the Kozai Group and professor emeritus. She was the Lucas Endowed Professor of Global Leadership and Executive Director of the Global Leadership Advancement Center at San Jose State University (2008-2020). An awardwinning teacher and scholar, Joyce has 160+ publications. Recent books include the Advances in Global Leadership series, Global Leadership: Research, Practices, and Development, Managing Across Cultures, and the SAGE Handbook of Contemporary CrossCultural Management.

Pamela M. Wells holds an M.S. in Industrial/Organizational Psychology and is lecturer in San Jose State University's Lucas College and Graduate School of Business. She teaches Management and Global Leadership and advises two student organizations, the Latino Business Students Association and the Burmese Myanmar Associated Students. She is a managing partner of Critical Moments Safety Training, LLC and is an educational consultant for Aiyin Inc. She is a recipient of San Jose State University's Master Teacher Award. 


\section{Appendix A. Personal Development Analysis and Action Plan}

After receiving and reflecting upon assessment feedback on global leadership competencies, students select a competency they desire to improve over the semester. Students develop a concrete and measurable plan, a personal development plan (PDP) to work on improving the specific competency on a daily basis and practice buffering negative thoughts (Beck, 1976).

\section{PDP Instructions to Students}

After reviewing and analyzing your assessment scores, reflections, and feedback, write a 2-3 page double-spaced plan. Please upload it to Canvas. Please cover the following items thoroughly, demonstrating good critical thinking, insight, and effort (Please include the headings for each question.)

1) SUMMARY: Based on the review of your assessment results and early class activities and exercises please summarize:

a) What you have learned in the course about intercultural competence and global leadership.

b) What you want to learn.

2) PERSONAL STRENGTHS: What are your personal strengths in the skill areas we have studied? Use the feedback from your assessments and simulations to support your analysis.

3) PERSONAL WEAKNESSES: What are your personal weaknesses in these skill areas? Use the feedback from your assessments and simulations to support your analysis.

4) ACTION PLAN: Write a thorough action plan to improve one of your major weaknesses. What specifically will you do to develop this weakness by the end of the course? Why are you choosing this goal? Action plans should be specific and measurable and include a deadline. Here's a good example: "I am going to take a more active role in team meetings because this is important in my work role. I will volunteer to be the team facilitator in at least one meeting during this semester. In all other meetings, I am going to make at least two process interventions to help the team function more effectively. To prepare myself, I am going to carefully observe other students who are excellent leaders, and I will read two articles on team leadership. I will also design an evaluation form on my team participation and ask my team to use it to evaluate me after the meeting I facilitate. Based on their feedback, I will continue working on possible weak areas during the rest of this course.”

To ensure on-going reflection and instructor support, "weekly email reports" (or blog reports) are sent to the instructor, which acts as an accountability mechanism (Burke \& Saks, 2009) to keep students engaged in the PDP process throughout the term. They are not graded on the content of their emails, but they lost points if they do not send the email on the due date.

Students are not evaluated against each other or to some standard in terms of the degree of progress they make; instead, they are rewarded for simply pursuing their personalized plan. The final self-reflection report is graded by the instructor in comparison 
to those of their class cohort (for a comprehensive description of the PDP process, please see Mendenhall et al., 2013).

Syllabus sample excerpt: Based on the assessments used in class, select a global managerial competency that you would need to improve in order to enhance your success on your overseas assignment. Develop a concrete plan to improve in this area and work your plan every week throughout the semester. Report to the instructor every Monday morning, via email, on the results you experienced during the past week of working your plan. In these emails feel free to update your plan based upon your progress. Penalties will occur if the email reports are late or ignored. At the end of the semester, write a seven-page (minimum) analysis of your personal development program, which includes a description of your current progress to date, what you learned about "how to learn" from the experience, and other learning insights the project triggered within you.

\section{Final PDP Report Instructions}

At the end of the course, write and upload a 2-page report on your efforts and results related to your action plan. Please answer each of the following questions thoroughly.

1. What specifically did you do to improve yourself?

2. How did that work out -- how were you successful or unsuccessful?

3. Why did you obtain these results?

4. Is there any difference between your pre and post IES results? Why? Please answer this question thoroughly.

5. What have you learned about yourself as a result of the whole PDP process?

6. How are you planning to apply in your career what you've learned about personal development as a result of the assessment/PDP process? 


\section{Appendix B. Resources for Simulations}

\begin{tabular}{|c|c|}
\hline GC ACTIVITIES* & Simulation Resources \\
\hline $\begin{array}{l}\text { Personal Assessment Instruments } \\
\text { \& PDP (self-awareness } \\
\text { \& intercultural effectiveness) }\end{array}$ & $\begin{array}{l}\text { Personal Assessment Instruments } \\
\text { Aperian Global. (2003). Globesmart. } \\
\text { https://www.globesmart.com/features/work-style-profile/. } \\
\text { Mendenhall, M. E., Stevens, M. J., Bird, A., Oddou, G. R., \& Osland, } \\
\text { J. S. (2011). The Intercultural Effectiveness Scale technical report. } \\
\text { The Kozai Group. } \\
\text { Watson Glazer Critical Thinking Pearson Education. (2014). } \\
\text { Watson-Glaser II Critical Thinking Appraisal Profile Report. } \\
\text { Retrieved from } \\
\text { http://www.thinkwatson.com/assessments/watsonglaser/profile- } \\
\text { report Pearson TalentLens. (2011). } \\
\text { PDP } \\
\text { Mendenhall, M., Burke, L. A., Arnardottir, A. A., Oddou, G., \& } \\
\text { Osland, J. (2020). “Making a Difference in the Classroom: } \\
\text { Developing Global Leadership Competencies in Business School } \\
\text { Students.” In L. Zander (ed.) Handbook of Global Leadership: } \\
\text { Making a Difference, pp. 330-349. Cheltenham, UK: Edgar Elgar. }\end{array}$ \\
\hline $\begin{array}{l}\text { BARNGA (intercultural } \\
\text { effectiveness) }\end{array}$ & $\begin{array}{l}\text { Thiagarajan, S. \& Thiagarajan, R. (1980). Barnga: A simulation } \\
\text { game on cultural clashes. The Thiagi Group. } \\
\text { https://www.thiagi.com/thiagi-store/barnga-25th-anniversary- } \\
\text { edition?rq=Barnga. }\end{array}$ \\
\hline $\begin{array}{l}\text { BAFA BAFA } \\
\text { (cultural entry) }\end{array}$ & $\begin{array}{l}\text { Shirts, R. G. (1977). Bafa Bafa: A cross culture simulation. Del Mar, } \\
\text { CA: Simile. }\end{array}$ \\
\hline $\begin{array}{l}\text { ECOTONOS } \\
\text { (multicultural teams) }\end{array}$ & $\begin{array}{l}\text { Hofner Saphiere, D. (2006). Ecotonos: A Simulation for } \\
\text { Collaborating Across Cultures. Cultural Detective. }\end{array}$ \\
\hline $\begin{array}{l}\text { Cultural Observation Report (global } \\
\text { mindset \& cultural entry) }\end{array}$ & Created for the GLLab by Joyce S. Osland. \\
\hline $\begin{array}{l}\text { THE OWL (intercultural } \\
\text { communication) }\end{array}$ & $\begin{array}{l}\text { Gochenour, Theodore. Beyond Experience: The Experiential } \\
\text { Approach to Cross Cultural Education. Yarmouth, Maine: World } \\
\text { Learning Inc., } 1993 .\end{array}$ \\
\hline $\begin{array}{l}\text { STAR TREK video test (int. } \\
\text { communication) }\end{array}$ & $\begin{array}{l}\text { Based on episode "Darmok at Tenagra", Season 5, episode 02, } \\
\text { Star Trek: The Next Generation. }\end{array}$ \\
\hline $\begin{array}{l}\text { DAIMLER } \\
\text { (multicultural teams) }\end{array}$ & $\begin{array}{l}\text { Exercise developed for the GLLab by Drs. Juergen Deller and } \\
\text { Juergen Deter, Luneburg University, Leuphana, Germany. }\end{array}$ \\
\hline $\begin{array}{l}\text { ARACRUZ CELLULOSE (stakeholder } \\
\text { dialogue) }\end{array}$ & $\begin{array}{l}\text { Reade, C., Todd, A., Osland, A. \& Osland, J. (2008). "Poverty and } \\
\text { the multiple stakeholder challenge for global leaders." Journal of } \\
\text { Management Education, 32(6): } 820-840 \text {. }\end{array}$ \\
\hline $\begin{array}{l}\text { Social Innovation Project } \\
\text { (innovation, design thinking, } \\
\text { teams) }\end{array}$ & $\begin{array}{l}\text { Osland, J. \& Lester, G. (2020). “Developing Socially Responsible } \\
\text { Global Leaders and Making a Difference: Global Leadership Lab } \\
\text { Social Innovation Projects.” In L. Zander (ed.) Handbook of Global } \\
\text { Leadership: Making a Difference. Cheltenham, UK: Edgar Elgar, pp. } \\
\text { 350-363. }\end{array}$ \\
\hline $\begin{array}{l}\text { ALPHA BETA (GC competencies in } \\
\text { negotiation) }\end{array}$ & $\begin{array}{l}\text { Gladwin, T. (2010). Alpha Beta Negotiation. } \\
\text { Public Domain Exercise distributed by the Dispute Resolution } \\
\text { Research Center (DRRC) DRRC, Kellogg School of Management, } \\
\text { Northwestern University. }\end{array}$ \\
\hline
\end{tabular}

